\title{
ENSINANDO A SER MULHER: UM ESTUDO DO DISCURSO PEDAGÓGICO DO ALMANAQUE DA FAMÍLIA (1947)
}

\author{
TEACHING TO BE A WOMAN: A STUDY OF PEDAGOGICAL \\ DISCOURSE IN THE ALMANAQUE DA FAMÍLIA (1947)
}

\author{
Ariana Pereira da Silva ${ }^{1}$ \\ Aguimario Pimentel Silva ${ }^{2}$ \\ Instituto Federal de Alagoas
}

\section{RESUMO}

O trabalho é um estudo sobre o discurso pedagógico do Almanaque da Família de 1947, que se configurava como um produto da imprensa feminina e orientava as leitoras a assumirem o modelo do que seria, à época, uma "mulher moderna". A partir do aporte teórico da Análise do Discurso, o objetivo é investigar como o conteúdo da publicação produziu determinados sentidos em relação à mulher da década de 1940. Destacam-se os modos de funcionamento desse discurso, observandose a ênfase dada ao lugar central da mulher no âmbito doméstico, visto como uma espécie de missão essencialmente feminina. Utiliza-se a discussão proposta por Orlandi $(1994,2006) \mathrm{em}$ relação ao discurso pedagógico, tomado como um discurso de tipo autoritário. Além disso, a análise centra-se na noção de memória discursiva, buscando compreender como a ideologia patriarcal construiu, por meio de efeitos de evidência, um modelo feminino socialmente legitimado. A partir das análises, é possível perceber que, de acordo com as condições de produção que o determinavam, o Almanaque da Família ajudou a (re)produzir uma representação feminina conservadora, ancorada no discurso religioso que sustentava o imaginário social da época.

PALAVRAS-CHAVE: Análise do Discurso. Discurso pedagógico. Gênero. Imprensa feminina.

\begin{abstract}
:
This paper is a study about the pedagogical discourse present in the Almanaque da Familia of 1947, which was configured as a product of a female press and guided readers to assume the model of what would be, at the time, a "modern woman". From the theoretical contribution of Discourse Analysis, the objective is to investigate how the content of the publication produced certain meanings in relation to the woman of 1940s. We highlight the functioning of this discourse, observing the emphasis given to the central place of women at home, seen as a kind of essentially feminine mission. We use the discussion proposed by Orlandi $(1994,2006)$ about pedagogical discourse, taking it as an authoritarian discourse. In addition, the analysis focuses on the notion of discursive memory, seeking to understand how patriarchal ideology built, through effects of evidence, a socially legitimated female model. It is possible to realize that, according to the conditions of production that determined it, the Almanaque da Familia produced a conservative female representation, anchored in the religious discourse that supported the social imaginary of the time.
\end{abstract}

KEYWORDS: Discourse Analysis. Pedagogical discourse. Gender. Female press.

\footnotetext{
${ }^{1}$ Licenciada em Pedagogia pela Universidade Federal de Alagoas (Ufal). Especialista em Linguagem e Práticas Sociais pelo Instituto Federal de Alagoas (Ifal). E-mail: ariany15.2009@gmail.com.

2 Doutorando em Linguística pela Universidade Federal de Pernambuco. Orientador do trabalho. Professor do Programa de Pós-graduação em Linguagem e Práticas Sociais do Instituto Federal de Alagoas (PPGLPS/Ifal). E-mail: aguimariopimentel@gmail.com.
} 


\section{INTRODUÇÃO}

A imprensa é um aparelho ideológico que adquiriu importante relevância nas sociedades modernas. Através dela, realiza-se um trabalho de produção de sentidos que passa, ao mesmo tempo, pela reprodução e pela transformação dos discursos existentes em um determinado momento histórico. Assim, o trabalho com os produtos da imprensa está diretamente relacionado à investigação das condições (sociais, culturais, políticas) que definem e regulam, para um ambiente sociocultural, as práticas discursivas legitimadas. Nossa abordagem da imprensa periódica parte da premissa de que ela mantém relações com o imaginário social constituído na/pela sociedade na qual circula, e esse fato tem implicações relevantes para o funcionamento dos processos discursivos nos produtos da comunicação.

Neste trabalho, construímos uma análise a respeito dos sentidos produzidos pelo Almanaque da Família de 1947, periódico que circulou na cidade do Rio de Janeiro, tendo como autor e proprietário D. A. C. Brandão. O anuário apresentava ensinamentos acerca de como a mulher do período precisava portar-se perante a sociedade e dentro de seu lar, para que conseguisse ser uma boa dona de casa, uma esposa admirável e uma mãe exemplar. No referido material, é possível encontrar diversas orientações/sugestões colocadas para que a mulher do período pudesse se adaptar às características daquilo que se considerava a "época moderna". Isso incluía dicas sobre os cuidados domésticos, a beleza, a moda e a educação dos filhos.

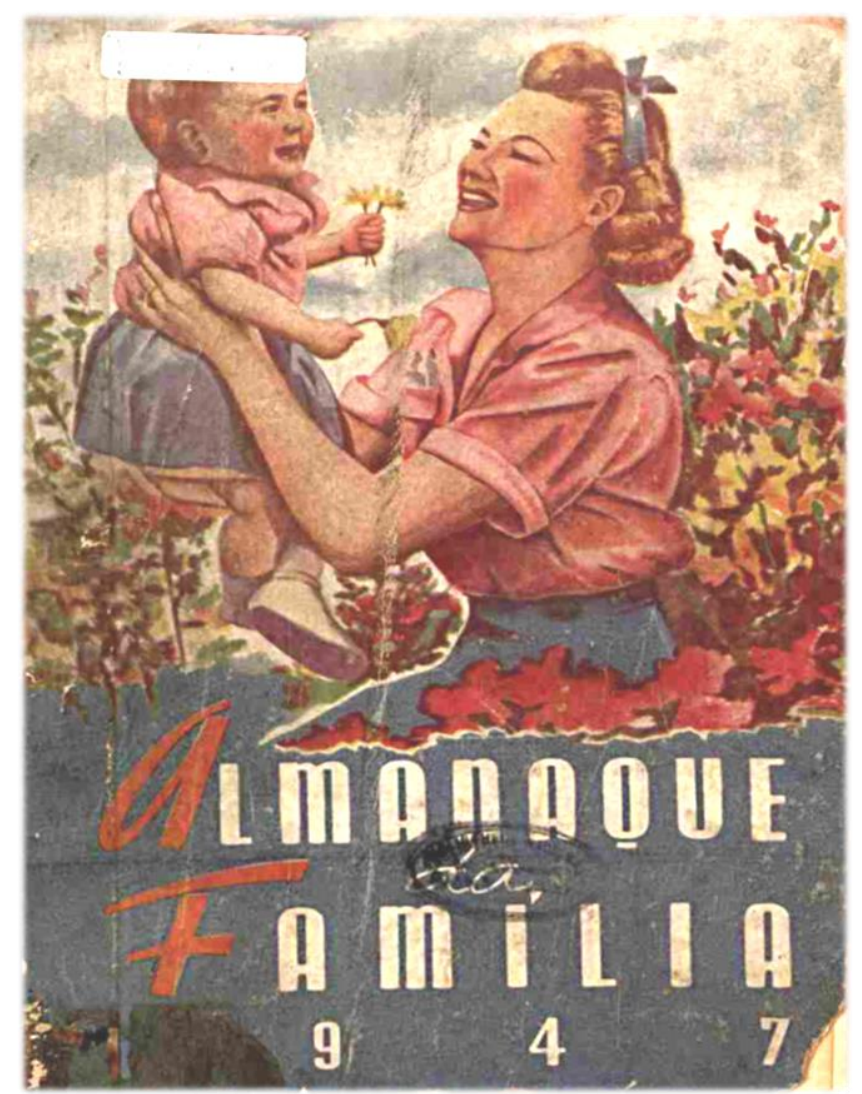

Figura 01 - Capa do Almanaque da Família.

Fonte: Almanaque da Família, 1947.

A própria capa do almanaque (figura 01) apresenta um conjunto de traços que constituíam, à época, o imaginário social acerca da mulher. Nela, vemos a retomada de uma memória de sentidos sobre a feminilidade, constituída nas/pelas práticas discursivas. A memória discursiva, para 
Pêcheux (2015, p. 52), seria "[...] aquilo que, face a um texto que surge como acontecimento a ler, vem restabelecer os 'implícitos' (quer dizer, mais tecnicamente, os pré-construídos, elementos citados e relatados, discursos-transversos, etc.)". Na materialidade do periódico, a capa referencia a memória discursiva construída em torno da mulher-mãe, veiculando a imagem de uma mulher que se define, especialmente, por sua ligação com o exercício da maternidade. A imagem faz-nos pensar em uma mulher-mãe feliz, realizada com a condição em que se encontra. Além disso, o registro em um campo florido parece encaminhar o reforço de tal efeito de sentido.

Nosso trabalho está vinculado à Análise do Discurso (doravante AD) pechêuxtiana, partindo da premissa de que os discursos são produzidos, no meio social, a partir de determinadas formações ideológicas que afetam os sujeitos nas diversas situações de uso da linguagem das quais eles participam. Assim, o discurso, tomado enquanto "efeito de sentido entre interlocutores" (PÊCHEUX, 2014), é sempre determinado por tais condições de produção. À luz da teoria da Análise do Discurso, pois, trataremos das formas por meio das quais a mulher era representada, no período, e de qual(is) era(m) o(s) discurso(s) a ela imposto(s) pela sociedade. Nesse sentido, observaremos como as representações veiculadas pelo Almanaque da Família estiveram atreladas ao imaginário social existente em relação à mulher brasileira da década de 1940.

Como afirma Saffioti (1987), a figura feminina sempre foi alvo da imposição de certos "deveres". Na visão da autora, tais deveres são determinados pela ação das instituições sociais, especialmente da família, da igreja e da escola, caracterizadas por Althusser (1985) como aparelhos ideológicos do Estado.

A identidade social da mulher, assim como a do homem, é construída através da atribuição de distintos papéis, que a sociedade espera ver cumpridos pelas diferentes categorias de sexo. A sociedade delimita, com bastante precisão, os campos em que pode operar a mulher, da mesma forma como escolhe os terrenos em que pode atuar o homem. (SAFFIOTI, 1987, p. 8).

A ideologia patriarcal - sobre a qual se estruturou, em grande parte, a vida social brasileira - determina o que seriam os lugares próprios do homem e da mulher, de modo que estabelece por meio da instituição de efeitos de evidência - o que é esperado de cada um dos sexos dentro da sociedade. Nesse trabalho de imposição, vão sendo construídas determinadas formações imaginárias que definem as próprias representações que os sujeitos fazem de si mesmos e dos outros. Ou seja: pelo trabalho da ideologia, determinados sentidos vão sendo estabilizados/regularizados, o que faz com que os lugares do homem e da mulher passem a ser vistos como naturais, como algo que "sempre foi assim". É nesse domínio de um "universo logicamente estabilizado" (PECHEUX, 2008) que são formuladas as representações e, consequentemente, os sentidos que elas fazem circular.

Na perspectiva da AD, o discurso é compreendido como um produto social. Assim, ele é condicionado pelas formações ideológicas que afetam os sujeitos em sua constituição. As formações ideológicas exercem um trabalho sobre o modo como determinados sentidos são produzidos em determinadas situações. A partir da consideração do discurso como um efeito do trabalho com a linguagem, Pêcheux (1995, p. 160) defende que

[...] o sentido de uma palavra, de uma expressão, de uma proposição, etc., não existe em "si mesmo" (isto é, em uma relação transparente com a literalidade do significante), mas, ao contrário, é determinado pelas posições ideológicas que estão em jogo no processo sócio-histórico no qual as palavras, expressões e proposições são produzidas (isto é, reproduzidas). [...] as palavras, expressões, proposições, etc., mudam de sentido segundo as posições sustentadas por aqueles que as empregam [...].

Podemos dizer que o discurso é uma construção social, ou seja, é no interior das relações sociais que ele se constitui. De acordo com Orlandi (1994), a construção social de um indivíduo 
passa pela ideologia, por formações imaginárias que colocam o sujeito em relação com suas condições de existência: a ideologia é interpretação de sentidos em certa direção, determinada pela relação da linguagem com a história, em seus mecanismos imaginários. Para a autora, é a ideologia que condiciona a relação mundo-linguagem. No entanto, essa relação não é intrínseca. O imaginário se constitui a partir das relações sociais que se estabelecem no/pelo discurso, fornecendo as imagens que condicionam a interlocução entre dois ou mais sujeitos. Nessa perspectiva, nos sentidos que são produzidos nas práticas de linguagem, intervêm a ideologia e os efeitos imaginários.

\title{
10 Almanaque da família e o discurso pedagógico
}

O almanaque inicia-se com uma "carta às leitoras". Logo, podemos perceber que se trata de um periódico dirigido ao público feminino. Assim, consideramos que se trata de um exemplar da chamada imprensa feminina. De acordo com Silva (2019, p. 107), no desenvolvimento da indústria comunicacional no Brasil, "[...] tal modelo de imprensa pretendeu-se corolário de uma proposta de desenvolvimento social que levasse em consideração, sobretudo, o papel intelectual exercido pela mulher no seio da sociedade".

Como um periódico feminino, o Almanaque da Família era composto de uma grande variedade de conteúdos, voltados, em sua maioria, para questões ligadas à administração do lar doméstico e à educação dos filhos. O tom pedagógico presente no jornal é evidenciado a partir do próprio título de alguns dos textos que ele veicula: "Como tirar manchas", "Como enfeitar os pratos", "As mamães devem saber", "Como tratar o seu refrigerador", "Normas da boa alimentação". Assim, o anuário procurava passar às leitoras determinados ensinamentos de ordem prática, no intuito de torná-las aptas para o desempenho de suas tarefas cotidianas. É por meio dessas injunções que o anuário vai significando a mulher, aproximando-a de uma imagem socialmente aceita.

Da carta de abertura do almanaque, tomamos a nossa primeira sequência discursiva para análise:

\begin{abstract}
$\mathrm{SD}^{3}$. [...] No lar, na sociedade, no trabalho, ou em qualquer parte, a mulher nivelou-se também ao homem no que diz respeito à organização e administração "escriturada". De hoje em diante, a mulher pode eliminar as clássicas exclamações tão dissonantes e tão prejudiciais ao bom-viver: "esqueci-me do aniversário de Mariazinha!..." "não sei onde gasto tanto dinheiro!..." "meus filhos não me dão tempo nem para ir ao cinema!..." "meu marido chega sempre aborrecido em casa..." "não tenho paciência para fazer o rol da roupa!..." e milhares de lamúrias mais ou menos assim... Isto não se justifica e só serve para prejudicar o lado risonho da vida, que todos têm o dever de apreciar o mais carinhosamente possível! (ÀS LEITORAS, 1947, p. 1).
\end{abstract}

A carta diz que a mulher "nivelou-se também ao homem" no que diz respeito à organização e à administração escriturada. Nesse sentido, podemos notar que o texto aponta uma pretensa igualdade entre homens e mulheres, o que parece encaminhar a relação com outras discursividades, a exemplo da luta de feições feministas que se desenhava no período. No entanto, os sentidos produzidos pelo texto mantêm-se no mesmo espaço do dizer, apresentando o ambiente doméstico como o lugar por excelência do feminino. Para Saffioti (1987), na estrutura social, é a mulher a designada para manter a organização da casa em todos os sentidos. Desde a arrumação doméstica até a criação dos filhos, é a ela que cabe prover a harmonia do lar: essa é sua "missão".

SD2. [...] E aqui abrimos o "Almanaque da Família". É um passo ousado que fazemos para colaborar com a mulher que ama o lar, aprecia o belo e adora os seus entes queridos...

${ }^{3} \mathrm{O}$ corpus do trabalho é constituído de um conjunto de sequências discursivas (SDs) extraídas de textos do almanaque. 
Esperamos que esta publicação possa ser utilizada continuamente, não só na parte referente às receitas que temos a pretenção de aconselhar a mulher espôsa, a mulher mãe e a mulher que está em vias de edificar o seu "doce lar"... Desejamos também que, anotando nos diversos formulários que se seguem, possam registrar, diariamente, os seus programas, aproveitando a vida que corre veloz e encontrando sempre um tempinho para o "lado côr de rosa" da existência humana! Que no fim dêstes trezentos e sessenta e cinco dias, si Deus quizer, possam, com êste anuário, apresentar aos seus distintos esposos, um "balancete" de trabalhos domésticos, de divertimentos salutares, de compromissos sociais, enfim, de tudo que pôde realizar "metòdicamente" e, melhor ainda, mostrar um "vultoso saldo de felicidade no seu lar...". (ÀS LEITORAS, 1947, p. 1).

É notável que o almanaque empenha-se em fornecer alguns ensinamentos sobre como a mulher deve apresentar-se ao seu esposo, de modo que não se mostre como inútil e desorganizada, mas como uma mãe/esposa dócil, organizada e empenhada em produzir, em seu lar, um "vultoso saldo de felicidade". Os termos "administração escriturada" (SD1) e "balancete" (SD2), presentes nas sequências recortadas, encaminham efeitos de sentido singulares: deslocados do campo semântico dos negócios, eles funcionam, metaforicamente, para referenciar rotinas de trabalho que são pautadas por relações de hierarquia. A necessidade de a mulher apresentar um balancete de seus trabalhos domésticos ao marido reflete a sua existência em uma posição de subordinação (como acontece num sistema hierárquico). Sustentada por uma memória discursiva que reafirma constantemente o lugar da mulher no espaço social, essa relação constrói-se por meio de imposições.

Tais imposições partem de um discurso no qual o sujeito usa meios que vão além da persuasão, aproximando-se da inculcação. Como nos diz Orlandi (2006), mais do que informar, explicar, influenciar ou mesmo persuadir, ensinar aparece como inculcar. É dessa forma que se apresenta o almanaque aqui analisado: nota-se, a partir dos ensinamentos presentes no periódico, a pretensão de inculcar, nas mulheres, determinadas noções acerca de como devem portar-se, não apenas para receberem elogios de seus esposos ou da sociedade, mas, principalmente, para que não sejam tidas como inúteis.

A inculcação é realizada por meio de um discurso de características autoritárias. De acordo com Silva (2019, p. 49), o discurso autoritário é aquele que não deixa espaço para outros sentidos, engendrando uma ilusão de reversibilidade pela restrição que impõe aos modos de significar. Em resumo, é um discurso que privilegia o aspecto parafrástico dos processos de linguagem, em detrimento do aspecto polissêmico, uma vez que está voltado para a manutenção de determinados saberes. A imprensa, por exemplo, é um aparelho ideológico que apresenta, em certo grau, esse traço autoritário, pois o discurso jornalístico procura ser didático, eliminando as ambiguidades e negando a pluralidade dos sentidos.

De acordo com Althusser (1985, p. 47), "os Aparelhos Ideológicos de Estado funcionam de um modo massivamente prevalente pela ideologia". É através do discurso, como materialização da ideologia, que a inculcação pode ser operada nos sujeitos. Silva (2019, p. 34) defende que o discurso se reproduz, nas estruturas de uma formação social, de forma a ser tomado como natural: "a ideologia tem como função produzir evidências imaginárias, isto é, produzir sentidos que se apresentam aos indivíduos como já estabelecidos, muitas vezes como realidades naturais e, por isso, imutáveis". Isso nos permite dizer que a (re)produção da ideologia e o seu funcionamento por meio da inculcação acontecem de uma forma que conduz à estabilização de determinados saberes.

Nesse sentido, o discurso do Almanaque da Família procura legitimar/naturalizar o que seria a missão da mulher no meio social, a partir do momento em que ele incita a mulher a realizar as tarefas do lar, almejando o sucesso na relação com seu esposo. Podemos notar essa incitação quando o almanaque diz que as instruções postas nele são para ajudar a mulher que ama o lar, aprecia o belo e adora seus entes queridos. É perceptível, nesse dizer, o traço injuntivo que caracteriza o discurso jornalístico. Os ensinamentos sobre como cuidar do lar aparecem de forma sutil, produzindo, dentre outros, o seguinte efeito de sentido: se a mulher ama o seu lar, gosta do que é bom e 
realmente quer o bem para as pessoas que ama, deve seguir o que há dentro do anuário para ter sucesso em suas tarefas, junto ao marido e diante da sociedade. O recorte faz-nos observar a representação imaginária daquilo que seria a mulher ideal para atender às necessidades da sociedade do período. Sobre essa questão, falaremos a seguir.

\section{O Almanaque da família e a construção de uma "mulher do lar"}

A AD se debruça sobre a compreensão do que é gerado a partir da articulação entre a língua e as ideologias de uma formação social, ou seja, sobre como se dá a produção de sentidos no meio social, observando-se a relação histórica entre a linguagem e as diferentes formações ideológicas que condicionam o seu uso.

Um dos itens que compõem o Almanaque da Família é o plano de trabalho no lar. Trata-se de um auxílio para a dona de casa no desenvolvimento de suas tarefas cotidianas, a fim de que ela possa ajustar o tempo diário/semanal para cumprir todas as suas funções domésticas. A intenção do plano de trabalho é fazer com que seu tempo não seja desperdiçado, mas aproveitado, de maneira que lhe permita dedicar-se aos deveres com a casa, com o marido, com os filhos e com ela mesma.

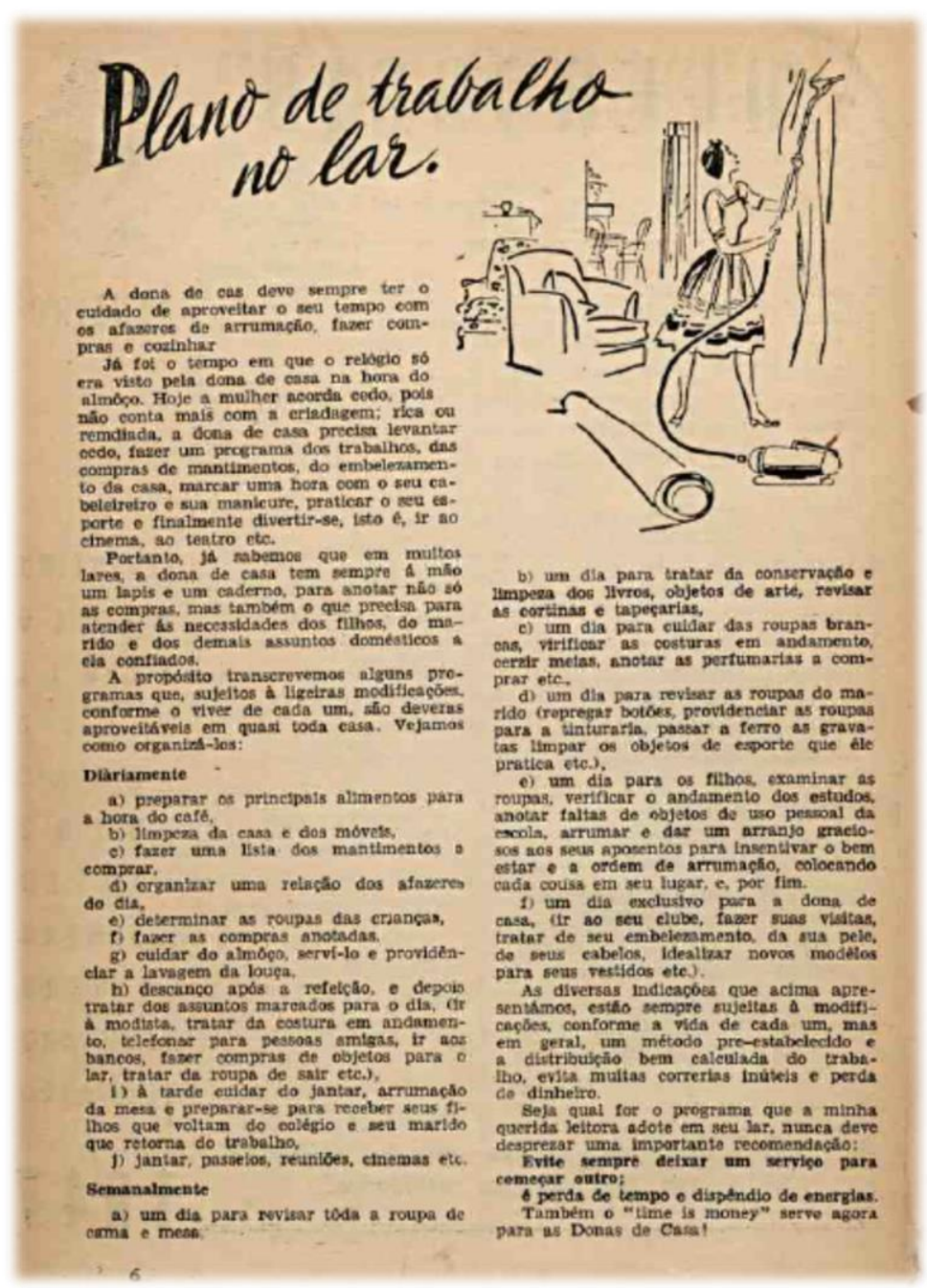

Figura 02 - Plano de trabalho no lar.

Fonte: Almanaque da Família, 1947. 
Esse tipo de material era bastante utilizado pela mulher da década de 1940. Como uma justificativa para sua própria existência, o Almanaque da Família argumentava que o modelo social havia mudado, uma vez que já não havia mais "criadagem". Assim, a mulher tornava-se a principal responsável pelo controle e pela organização das tarefas da vida doméstica. A SD3 apresenta um recorte da argumentação que é construída nas páginas do periódico:

SD3. Já foi o tempo em que o relógio só era visto pela dona de casa na hora do almôço. Hoje a mulher acorda cedo, pois não conta mais com a criadagem; rica ou remdiada [sic], a dona de casa precisa levantar cedo, fazer um programa dos trabalhos, das compras de mantimentos, do embelezamento da casa, marcar uma hora com o seu cabeleireiro e sua manicure, praticar o seu esporte e finalmente divertir-se, isto é, ir ao cinema, ao teatro etc. Portanto, já sabemos que em muitos lares, a dona de casa tem sempre á mão um lapis e um caderno, para anotar não só as compras, mas também o que precisa para atender ás necessidades dos filhos, do marido e dos demais assuntos domésticos a ela confiados. (PLANO, 1947, p. 6).

O padrão de mulher que o almanaque constrói não se desvincula dos saberes patriarcais que identificam o feminino com o espaço doméstico, mas, ao mesmo tempo, o periódico procura ajustar o seu discurso ao que seria a figura de uma "mulher moderna", alinhada às novas necessidades impostas pela sociedade do período. Essa "mulher moderna", no imaginário da época, é aquela que trabalha, que se mostra produtiva e, com isso, pode auxiliar o marido na administração da casa.

Schemes e Dobler (2015), em estudo que analisa a figura da mulher na sociedade dos anos 1940, a partir de sua circulação nas páginas da imprensa, percebem que as mulheres consideradas modernas eram aquelas que tinham mais destaque no espaço do jornal, por serem convidadas para festas, eventos sociais e filantrópicos, como também aquelas que anunciavam seus trabalhos nos periódicos. Nesse rol, incluíam-se as mulheres que ofereciam trabalhos de costura, as que prestavam serviços de enfermagem, as cartomantes, as que executavam serviços médicos, entre outras. Nota-se, portanto, a existência de uma relativa abertura para a atuação da mulher no espaço público, rompendo as fronteiras do lar doméstico.

Numa outra perspectiva, o efeito de sentido que é encaminhado pela noção de mulher moderna, nos textos do Almanaque da Família, não parece estar relacionado à quebra da dicotomia espaço público/espaço privado, mas à atuação da mulher enquanto responsável pela administração do lar. Assim, uma vez que "não conta mais com a criadagem", a mulher torna-se moderna ao incorporar a função social de responsável pela gestão do lar. A relação da mulher com o lar não é rompida, mas ressignificada. A "mulher moderna" representa uma nova posição dentro do mesmo espaço de (re)produção de sentidos. As discrepâncias entre os modelos femininos que são apresentados nas análises de Schemes e Dobler (2015), por um lado, e no conteúdo do almanaque, por outro, permitem a compreensão de que, neste último, há uma caracterização da mulher que é de ordem muito mais conservadora. Os dizeres sobre a mulher são, em grande parte, condicionados pelos saberes de um discurso religioso: "Que no fim dêstes trezentos e sessenta e cinco dias, si Deus quizer, possam, com êste anuário, apresentar aos seus distintos esposos, um "balancete" de trabalhos domésticos [...]".

Isso aponta a existência da tensão entre a paráfrase e a polissemia. $\mathrm{Na}$ SD3, podemos perceber a presença da paráfrase quando lemos que a mulher precisa atender às necessidades dos filhos, do marido e dos demais assuntos domésticos a ela confiados. Esse dizer reforça o discurso de que a mulher precisa ser/estar preparada para atender aos anseios de todos dentro do seu lar. A existência da polissemia é evidenciada, por exemplo, quando o almanaque diz que "também o 'time is money' serve agora para as donas de casa". Tem-se, novamente, uma expressão que é deslocada do campo semântico dos negócios para, por meio do discurso da eficiência, dar significado à relação entre a mulher e o lar. Assim como numa empresa, onde o trabalhador que para suas tarefas (ou que não apresenta o mesmo resultado que os demais colegas, no mesmo período de tempo) é tido 
como não produtivo, a mulher que não se organiza em relação ao tempo também está sujeita a essa forma de avaliação social.

A formulação "assuntos domésticos a ela confiados", encontrada no anuário, remonta à própria constituição histórica dos processos relativos à educação e à socialização femininas. $\mathrm{O}$ ensino para meninas passou a ser admitido, no Brasil, a partir de 1827. No entanto, as práticas de educação para a mulher estiveram, desde o início, voltadas para a inculcação de um modelo específico de sociabilidade. Existiam limitações no que se refere ao acesso ao conhecimento, pois as meninas deveriam ter educação escolar, apenas, até o primário, enquanto para os meninos as possibilidades se estendiam até o ensino superior. Conforme Silva (2019, p. 90-91),

\begin{abstract}
[...] as oportunidades, no campo da instrução secundária, estiveram restritas basicamente ao sexo masculino. Tal fato confirma a existência de meninas estudantes quase que unicamente nas turmas de ensino primário. De toda forma, os conhecimentos mais abstratos estavam excluídos do currículo feminino, que incluía, por sua vez, conhecimentos relativos às artes domésticas, o que mostrava, desde muito cedo, a preparação das alunas para as funções de esposa, mãe e dona de casa, nos termos da visão cultural dominante.
\end{abstract}

A inculcação de determinados saberes, de acordo com Orlandi (2006), é caracterizada por vários fatores que constituem a ordem social considerada, ou seja, ela está presente nas práticas discursivas, nas suas variadas formas. A inculcação, como função de um discurso pedagógico, visa a fixar conteúdos ideológicos, contribuindo, portanto, para a reprodução dos saberes. Sua eficácia está em não ser percebida como algo imposto, mas como algo natural. No caso específico que investigamos, o trabalho de produção de sentidos que é realizado pelo periódico visa a apresentar o que seria um conjunto de deveres naturalmente identificados com a figura feminina.

Considerando que um discurso é sempre um entre tantos efeitos de sentido, a apropriação desse discurso "inculcado" dá-se por meio da identificação com os sentidos veiculados, que nos ensinam aquilo que devemos saber (ORLANDI, 2006). Assim sendo, o discurso do almanaque, ao pretender ser pedagógico, retoma essa memória de uma mulher educada e preparada para assumir as tarefas do lar, sendo a única responsável por elas. Ao mesmo tempo, impõe os saberes dessa memória como saberes que devem ser seguidos e que não admitem questionamentos. Nesse sentido, suas posições são sustentadas/respaldadas por um discurso religioso de tom moralizante, a fim de que aquilo que está sendo ensinado/inculcado não possa ser posto em dúvidas.

O preparo das meninas a partir dos conhecimentos concernentes aos cuidados domésticos faz-nos refletir sobre outro ponto posto no discurso do almanaque: trata-se da forma como o periódico aborda o trabalho doméstico, apresentando-o como uma "missão" naturalmente pertencente à mulher e que, portanto, somente por ela pode ser desempenhada. Sobre esse pensamento, Saffioti $(1987$, p. 9) nos mostra que

A sociedade investe muito na naturalização deste processo. Isto é, tenta fazer crer que a atribuição do espaço doméstico à mulher decorre de sua capacidade de ser mãe. De acordo com este pensamento, é natural que a mulher se dedique aos afazeres domésticos, aí compreendida a socialização dos filhos, como é natural sua capacidade de conceber e dar à luz.

Podemos notar que essa identificação da mulher com a figura da dona de casa retoma a memória de sentidos do discurso religioso cristão, que atribui, tanto ao homem quanto à mulher, papéis específicos no seio da família. Podemos encontrar um exemplo dessa distinção no anuário:

SD4. Deus, si não lhe deu a força fisica, apanágio da masculinidade, deu-lhe, entretanto, a força moral, serena, imperturbável e tranquila deante os desvairos turbulentos dos homens. (A GRAÇA, 1947, p. 28). 
As palavras do almanaque nos permitem entender que há uma distinção entre força moral e força física, e que a primeira refere-se à mulher e a segunda ao homem, levando à compreensão de que essa força moral da mulher é o principal instrumento que a faz ser responsável por cuidar da família e, principalmente, por educar (moralmente) os filhos. As distinções entre essas duas expressões conseguem apontar o imaginário social da época construído para a mulher e para o homem. Notamos, também, que o almanaque referencia Deus como o responsável pela atribuição dessas características aos homens e às mulheres. Assim, o discurso de diferenciação dos sexos, apesar de ser uma construção histórica, no material analisado, apresenta-se como algo que é parte da natureza, parte da criação divina. Dessa forma, esse discurso torna-se incontestável, pois ninguém ousaria ir contra Deus, de acordo com o imaginário social da época.

De acordo com Dias (1987), o papel da igreja é o de manter controle sobre os indivíduos sociais e, para isso, se intitula como a voz de Deus para ensinar aos fiéis:

A voz de Deus é mediada pela arquidiocese. Esta por sua vez, está delimitada regionalmente num contexto social, econômico e político, implicando, necessariamente, algum tipo de relação com o Estado que deseja manter o controle sobre os cidadãos. (DIAS, 1987, p. 48).

Esse discurso da instituição religiosa (que, assim como a imprensa, é um aparelho ideológico) é produzido tendo em vista o exercício da autoridade sobre os sujeitos que se colocam em processo de identificação com a formação discursiva considerada. Dessa maneira, os dizeres se colocam de forma a não serem questionados. O discurso que vincula o que seria a suposta missão da mulher à figura da cuidadora do lar, por sua vez, é reproduzido em função do reconhecimento da autoridade do discurso religioso.

Em outras palavras: uma vez que a mulher, por sua condição natural de sexo, concebe um filho, fazem parte de sua missão, enquanto mulher, os cuidados com a educação dos filhos, os cuidados com o marido e os cuidados domésticos. O conteúdo do Almanaque da Família é guiado por essa identificação com uma formação discursiva de traços patriarcais, inculcada de forma a parecer natural. Como um produto da imprensa feminina, o periódico ensina às suas leitoras que cabe à mulher a missão de tomar conta de tudo que envolve o lar, e que ela deve agir de acordo com essa determinação. Assim, a sociedade, como frisa Saffioti (1987), institui uma identidade básica entre as mulheres, que é a da "mulher/mãe/dona de casa", trabalhando no sentido de naturalizar essa imagem.

O que, para Saffioti (1987), aparece como algo naturalizado, Orlandi (2006) mostra como sendo o resultado de um processo (ideológico) de inculcação. Nesse sentido, as posições das duas autoras se complementam, apontando como nos são apresentadas as ideologias, aquelas que, como defende Pêcheux, são produtos sociais. Em suma: elas nos são inculcadas por meio da reprodução discursiva, conduzindo à naturalização de certas questões para atender às necessidades da dominação ideológica.

O plano de trabalho no lar trazido pelo anuário permite notar um reforço da ideia de que o espaço doméstico é missão da mulher. Assim se expressa o almanaque: "A dona de casa precisa sempre ter o cuidado de aproveitar o seu tempo com os afazeres de arrumação, fazer compras e cozinhar" (PLANO, 1947, p. 6). Esse reforço procura exigir da mulher que cumpra o seu papel enquanto ser de natureza feminina. O discurso de que o espaço do lar é restrito à mulher, devido à sua natureza, é determinado, ao mesmo tempo, por uma formação discursiva patriarcal e por uma formação discursiva cristã.

Segundo Siqueira (2017), é possível identificar, para uma formação ideológica, um modo de produção específico que a domina e um estado de relações de classe que a compõe. Tais relações dão espaço a posições de classe específicas, que não constituem indivíduos, mas configuram formações que mantêm, entre si, relações de antagonismo, aliança ou dominação. Assim, como, para Pêcheux (1995), cada formação discursiva tem relação direta com uma dada formação 
ideológica, consideramos que o almanaque aproxima-se do discurso cristão (autoritário), utilizando-se do reconhecimento que a ele é concedido para que, assim, consiga atingir seu objetivo, que é a manutenção do discurso segundo o qual os papéis sociais atribuídos aos sujeitos, em uma sociedade, dependem das condições biológicas desses sujeitos.

\section{CONSIDERAÇÕES FINAIS}

Diante do exposto neste trabalho, pudemos perceber a relação do conteúdo do Almanaque da Família com o imaginário social da época, que definia os lugares de atuação do homem e da mulher a partir da influência de saberes patriarcais e de saberes cristãos, em um processo de inculcação com vistas à naturalização dos sentidos.

O caráter pedagógico do anuário é explicitado na forma como ele ensina as mulheres a cuidarem de seu lar. Esse discurso pedagógico produz efeitos de sentido que fixam conteúdos ideológicos, de modo que não são notados como algo impositivo, mas como algo natural. Assim, o discurso adquire eficácia. $\mathrm{O}$ anuário visa a mostrar às mulheres o que seria a sua missão: cuidar do lar, ser uma boa mãe e ser uma esposa que preza pelo bem do marido. É sobre essa ideia de uma "missão da mulher" que o almanaque se apoia, permitindo a compreensão de que seu discurso faz uso da paráfrase para inculcar/naturalizar, nas mulheres, qual é o seu dever dentro da sociedade e quais papéis desempenhar.

O material analisado, apesar de demonstrar o conservadorismo que é próprio do sistema patriarcal, é caracterizado por alguns traços polissêmicos, como, por exemplo, quando o almanaque nos diz que, no lar, na sociedade ou no trabalho, a mulher nivelou-se ao homem, o que aponta para a proposição de uma existência igualitária entre os sexos. Há uma tensão dos sentidos, apesar da linha conservadora que marca a publicação. Dessa maneira, podemos dizer que o discurso do periódico apresenta-se mais parafrástico do que polissêmico, ou seja, não rompe com as discursividades às quais se vincula. Em vez disso, produz um discurso que se ancora numa memória estabilizada de sentidos sobre a mulher e sobre o seu lugar social, agindo por meio da paráfrase e do retorno a uma memória constantemente atualizada.

\section{REFERÊNCIAS BIBLIOGRÁFICAS}

A GRAÇA e o sorriso da mulher. Almanaque da Família, Rio de Janeiro, p. 28, 1947.

ALTHUSSER, Louis. Ideologia e aparelhos ideológicos do Estado. 3. ed. Lisboa: Editorial Presença, 1985.

ÀS LEITORAS. Almanaque da Família. Rio de Janeiro, p. 1, 1947.

DIAS, Romualdo. De Deus ao seu povo. In: ORLANDI, Eni Puccinelli (org.). Palavra, fé, poder. Campinas, SP: Pontes, 1987. p. 43-51.

ORLANDI, Eni Puccinelli. A linguagem e seu funcionamento: as formas do discurso. 4. ed. Campinas, SP: Pontes, 2006.

ORLANDI, Eni Puccinelli. Discurso, imaginário social e conhecimento. Em Aberto, Brasília, ano 14, n. 61, p. 53-59, jan./mar. 1994.

PÊCHEUX, Michel. Análise Automática do Discurso (AAD-69). Tradução de Eni Puccinelli Orlandi. In: GADET, Françoise; HAK, Tony (org.). Por uma análise automática do discurso: uma introdução à obra de Michel Pêcheux. 5. ed. Campinas, SP: Editora da Unicamp, 2014. 
PÊCHEUX, Michel. O discurso: estrutura ou acontecimento. 5. ed. Campinas, SP: Pontes, 2008.

PÊCHEUX, Michel. Papel da memória. In: ACHARD, Pierre et al. Papel da memória. 4. ed. Campinas, SP: Pontes Editores, 2015.

PÊCHEUX, Michel. Semântica e discurso: uma crítica à afirmação do óbvio. Tradução de Eni Puccinelli Orlandi et al. 2. ed. Campinas, SP: Editora da Unicamp, 1995.

PLANO de trabalho no lar. Almanaque da Família, Rio de Janeiro, p. 6, 1947.

SAFFIOTI, Heleieth. O poder do macho. São Paulo: Moderna, 1987.

SCHEMES, Cláudia; DOBLER, Grazziela. A representação da mulher nos anos 1940 em Novo Hamburgo/RS. Revista Conhecimento Online, Novo Hamburgo, ano 7, v. 2, p. 3-13, 2015. Disponível em:

https://periodicos.feevale.br/seer/index.php/revistaconhecimentoonline/article/view/134. Acesso em: 05 dez. 2019.

SILVA, Aguimario Pimentel. Imprensa, gênero e poder: discursos sobre a educação da mulher no Brasil Império. São Cristóvão, SE: Editora da Universidade Federal de Sergipe, 2019.

SIQUEIRA, Vinicius. Formação discursiva e interdiscurso - Michel Pêcheux. Colunas tortas, São Paulo, 2 abr. 2017. Disponível em: https://colunastortas.com.br/formacao-discursiva-einterdiscurso-michel-pecheux. Acesso em: 05 dez. 2019. 